\title{
OPTIMIZATION AND PREPARATION OF SOLID LIPID NANOPARTICLE INCORPORATED TRANSDERMAL PATCH OF TIMOLOL MALEATE USING FACTORIAL DESIGN
}

\author{
PARVEEN KUMAR ${ }^{1,2^{*}}$, BIRENDRA SHRIVASTAVA ${ }^{1}$, MADAN MOHAN GUPTA ${ }^{1,3}$, ANIL KUMAR SHARMA ${ }^{2}$
}

${ }^{1}$ School of Pharmaceutical Sciences, Jaipur National University, Jaipur, Rajasthan, India, ${ }^{2}$ Shri Ram College of Pharmacy, Karnal, Haryana, India, ${ }^{3}$ Laboratory of Pharmaceutical Formulation Design and Development, School of Pharmacy, Faculty of Medical Sciences, The University of the West Indies, Trinidad and Tobago, West Indies

Email: praveenmoond@gmail.com

Received: 01 Aug 2019, Revised and Accepted: 23 Sep 2019

\begin{abstract}
Objective: Transdermal patch of timolol maleate was prepared in order to increase the permeability of the drug topically.

Methods: The timolol maleate (TM) loaded solid lipid nanoparticles (SLN) were prepared by the solvent evaporation method. For the optimization process full factorial (three-factor and three-level), hydroxypropyl methylcellulose (HPMC) range from 100 to $300 \mathrm{mg}$, ethylcellulose 100 to 200 gm and almond oil 3 to $4 \mathrm{ml}$. The response noted in form of tensile strength and percent drug release. These transdermal patches were evaluated for physical characterization like weight variation, thickness, percentage moisture absorption, percentage moisture loss, water vapor transmission rate, folding endurance, tensile strength, and content uniformity.
\end{abstract}

Results: Solid lipid nanoparticles of TM were optimized and prepared, the data presented that drug release percent ranged from 66.12 to $91.75 .2 \mathrm{FI}$ model was observed to fit for response \% drug permeation with a p and F value of 0.0271 and 4.50 . The tensile strength varies from 0.358 to 0.508 . The linear model was observed to fit for the tensile strength response with a p-value and F-value of<0.0001 and 52.41 .

Conclusion: The controlled release formulation of Timolol Maleate was successfully optimized and prepared, a study conducted to investigate the effect of different polymers and type of permeation time profiles from Timolol Maleate patches.

Keywords: Transdermal Patch, Optimization, Drug release, Tensile strength, ANOVA

(C) 2019 The Authors. Published by Innovare Academic Sciences Pvt Ltd. This is an open access article under the CC BY license (http://creativecommons.org/licenses/by/4.0/) DOI: http://dx.doi.org/10.22159/ijap.2019v11i6.35184

\section{INTRODUCTION}

Cardiovascular disease (CVD) is viewed as multifactorial in origin. Because of the contributions of numerous elements, is influenced by different kinds of disorder. Strasser, 1990, has expressed it [1] that there are contributions of in excess of 250 risk factors have been related to cardiovascular disease. Out of those risk factors, the fundamental reasons for the episode of cardiovascular ailments are viewed as inherited, age and gender. It is mainly influenced by the individual way of life and its method of living. The major risk factors associated with cardiovascular disease remain to increase in blood pressure and high blood fats along. Aside from these factors, way of life with an ordinary intake of smoking and tremendous utilization of saturated fats causes distinctive kinds of cardiovascular disease. More often than not, it is additionally a result of less physical idleness or exercise [2].

Day by day, the mortality rate has been increasing all through the world. It has been accounted for, that in the western world real passing happens as a result of heart diseases, cardiovascular disease (CVD) and inappropriate functioning of the circulatory network. This report has been representing around $31 \%$ of the complete worldwide death rate [3]. British Heart Foundation; 2000 announced that close around 4.35 million passing's happened each year in Europe alone [4]. Out of these close, around $80 \%$ of death is among youngsters (<65 y). There are mainly different stages of hypertension.

a). Primary or essential hypertension b). Secondary hypertension

Development of essential hypertension conditions is on the grounds that abnormally high in the blood volume in the body and it grows bit by bit and over a long time or years.

The event of secondary hypertension is observed to be close around $5-6 \%$ of every hypertensive case. In the vast majority of cases, renal malfunctioning contributes to the major role for an event of secondary hypertension. There are diverse variables like race/ethnicity, age, education level, origin of birth, low family pay, diabetes, heftiness, handicap status and protection are the thought processes in the critical dissimilarities in the predominance of hypertension [5].

As indicated by sources, from 1999 to 2009 the death rate from hypertension expanded to be around 17.1 percent [6]. What's more, the real level of death rises to $43.6 \%$. The expansion rate of the dreariness and mortality is high that Healthy People 2020 chose to diminish the hypertension recurrence among grown-ups by 26.9 percent and to expand the pervasiveness of hypertension control among grown-ups with hypertension to 61.2 percent [7]. The transdermal patches were prepared to avoid the first-pass metabolism of drug and solid nanoparticles increase the permeability of the drug through topical route.

\section{MATERIALS AND METHODS}

\section{Material}

Timolol maleate (TM) was generously gifted by Gangwal chemicals Pvt. Ltd, Mumbai, India. Tween 20 and polyethylene glycol (PEG) 400 was purchased from SD fine chemicals, compritol 888 ATO from Gettefosse (India) Pvt. Ltd; Mumbai, lutrol F68 from BASF, India. Hydroxypropyl methylcellulose (HPMC K 100M) was gifted by Colorcon Asia Pvt. Ltd; Goa, analytical grades of orthophosphoric acid and nylon membrane filters $(0.45 \mu \mathrm{m})$ were purchased from Fisher Scientific (Mumbai, India). All aqueous solutions were prepared using Milli Q/Elix water (Millipore, MoscheimCedex, France). All other chemicals used were of analytical grade.

\section{Methods}

\section{Preparation of drug-loaded SLN of TM}

In order to prepare Solid Lipid Nanoparticles (SLN) of TM, the weighed quantity of Lutrol F68 and tween 80 are added to purified water under stirring to get a clear solution and the temperature maintained at $85-90{ }^{\circ} \mathrm{C}(5 \%$ overages of purified water taken to compensate loss on heating), Compritol 888 ATO is heated to melt to this Timolol maleate is added under stirring to get a clear 
solution. Above solutions mixed together using ultratrax stirrer at $13000 \mathrm{rpm}$ for $15 \mathrm{~min}$ by maintaining the temp at $85-90{ }^{\circ} \mathrm{Cafter}$ homogenization the dispersion is kept aside to come to room temperature $[8,9]$.

\section{Preparation of SLNs transdermal patches}

Transdermal patches containing Timolol Maleate were prepared up by solvent casting technique-utilizing mercury a role as substrate. Different formulations were formulated utilizing different grades of hydroxyl propyl methylcellulose (HPMC) for example HPMC K100M, HPMC $50 \mathrm{cps}$, and ethyl acetate, distinctive level of polyethylene glycol and $100 \mathrm{mg}$ of optimized nanoparticles added gradually to the solution and mixing for $30 \mathrm{~min}$. The mold was kept on a mercury surface. Around $4 \mathrm{ml}$ of the prepared solution was poured on the mercury $[10,11]$. The rate of evaporation was constrained by inverting the funnel over the mold. After $12 \mathrm{~h}$, the dried patches were cut into $2.2 \mathrm{~cm}$ width, enclosed by aluminium foil and put away over fused calcium chloride in a desiccator at room temperature for further use.

\section{Statistical optimization of the formulation variables using a factorial experimental design}

For the better physic-synthetic property of prepared patch was an attempt to utilize HPMC 50cps and ethyl cellulose as independent factor X1 and X2 for the optimization of the final formulation by using full factorial $3^{3}$ (three-factor and three-level) by using Design Expert 11 Trial Version Software. Permeation of pure drug improves with almond seed oil and it was adequate to accomplish focused on targeted flux to maintained therapeutic concentration and controlled release of drug for a predetermined period. In this way, concentration of almond oil as a permeation enhancer select as another independent factor X3. The design involved two dependent variables (Y1 and $\mathrm{Y} 2)$ and above mentioned three independent variables (X1, X2, and $\mathrm{X} 3$ ). The dependent variable $\mathrm{Y} 1$ was tensile strength (TS) of prepared patches, Y2 was percent drug release (table 1). After completion of statistical optimization experiments, polynomial equations and contour plots generated to study the effect of selected independent variables on dependent variables in order to identify the optimized drug-loaded transdermal patch.

Table 1: Variables and their levels in $3^{3}$ level factorial experiments design for patches

\begin{tabular}{|c|c|c|c|c|c|c|c|}
\hline \multicolumn{2}{|c|}{ Variables } & \multirow{2}{*}{$\frac{\text { Units }}{\mathrm{Mg}}$} & \multirow{2}{*}{$\begin{array}{l}\text { Type } \\
\text { Factor }\end{array}$} & \multirow{2}{*}{$\frac{\text { Low }}{-1}$} & \multicolumn{2}{|l|}{ Medium } & \multirow{2}{*}{$\frac{\text { High }}{+1}$} \\
\hline A- & HPMC & & & & 0 & & \\
\hline B- & Ethyle cellulose & $\mathrm{Mg}$ & Factor & -1 & 0 & & +1 \\
\hline $\mathrm{C}-$ & Almond Oil & $\mathrm{Ml}$ & Factor & -1 & - & & +1 \\
\hline & rength & $\mathrm{Kg} / \mathrm{mm} 2$ & Response & - & - & & - \\
\hline & lease & $\%$ & Response & - & - & & - \\
\hline Var & & & Low & Medium & & High & \\
\hline$A-$ & HPMC & & 100 & 200 & & 300 & \\
\hline B- & Ethylcellulose & & 100 & 150 & & 200 & \\
\hline C- & Almond Oil & & 3 & - & & 4 & \\
\hline
\end{tabular}

Physico-chemical parameter of the transdermal patch formulation was carried out in terms of weight variation, thickness, percent moisture absorption, percent moisture loss, water vapor transmission rate and folding endurance [12].

To analyze the adequacy of models, trial information, and experimental data were fitted to various polynomial models including linear, interactive, cubic and quadratic and statistical tests such as a sequential model sum of squares. Selected the highest order polynomial where the terms are significant and the model is not aliased. Highest order polynomial was selected in that the additional terms are significant and the model is not aliased.

\section{RESULTS}

Timolol maleate transdermal patches were prepared by using the solvent casting technique. For optimization process full factorial design ( $3^{3}$ three-factor and three-level), different 18 formulations prepared as per design at different level responses as tensile strength and \% drug release noted as per formulations (table 2). Formulation having the highest percent drug release $(91.75 \%)$ and highest tensile strength (0.508) prepared by using (table 3). HPMC 50 cps $300 \mathrm{mg}$, ethylcellulose $100 \mathrm{mg}$ and $4 \mathrm{ml}$ almond oil.

Table 2: Variables and their levels in 33 level full factorial experiments design for patches

\begin{tabular}{|c|c|c|c|c|c|}
\hline & Factor 1 & Factor 2 & Factor 3 & Response 1 & Response 2 \\
\hline \multirow[t]{3}{*}{ Std } & Run A: HPMC 50 & B: Ethyl & C: Almond & Tensile & \% Drug \\
\hline & Cps & Cellulose & Oil & Strength & Release \\
\hline & $\mathrm{Mg}$ & $\mathrm{Mg}$ & Ml & $\mathrm{Kg} / \mathrm{mm}^{2}$ & $\%$ \\
\hline 1 & 1100 & 100 & 3 & 0.369 & 66.12 \\
\hline 11 & 2200 & 100 & 4 & 0.453 & 76.91 \\
\hline 3 & 3300 & 100 & 3 & 0.494 & 81.41 \\
\hline 2 & 4200 & 100 & 3 & 0.451 & 72.45 \\
\hline 16 & 5100 & 200 & 4 & 0.358 & 72.49 \\
\hline 18 & 6300 & 200 & 4 & 0.485 & 78.45 \\
\hline 5 & 7200 & 150 & 3 & 0.429 & 70.45 \\
\hline 7 & 8100 & 200 & 3 & 0.386 & 68.35 \\
\hline 14 & 9200 & 150 & 4 & 0.437 & 72.61 \\
\hline 8 & 10200 & 200 & 3 & 0.456 & 71.32 \\
\hline 4 & 11100 & 150 & 3 & 0.403 & 69.43 \\
\hline 10 & 12100 & 100 & 4 & 0.401 & 69.34 \\
\hline 15 & 13300 & 150 & 4 & 0.503 & 83.45 \\
\hline 6 & 14300 & 150 & 3 & 0.478 & 77.59 \\
\hline 12 & 15300 & 100 & 4 & 0.508 & 91.75 \\
\hline 17 & 16200 & 200 & 4 & 0.459 & 73.48 \\
\hline 13 & 17100 & 150 & 4 & 0.382 & 70.26 \\
\hline 9 & 18300 & 200 & 3 & 0.479 & 78.32 \\
\hline
\end{tabular}


Table 3: Variables and their levels in 33 level factorial experiments design for patches

\begin{tabular}{|c|c|c|c|c|}
\hline Name & Units & Type & Low & High \\
\hline HPMC $50 \mathrm{cps}$ & $\mathrm{Mg}$ & Factor & 100 & 300 \\
\hline Ethylcellulose & $\mathrm{Mg}$ & Factor & 100 & 200 \\
\hline Almond oil & $\mathrm{Ml}$ & Factor & 3 & 4 \\
\hline Tensile strength & $\mathrm{Kg} / \mathrm{mm}^{2}$ & Response & Maxil & \\
\hline$\%$ Drug release & \%age & Response & Maxil & \\
\hline
\end{tabular}

Table 4: Fit summary model for the measured responses R1 and R2 for the patch, response 1: tensile strength

\begin{tabular}{llll}
\hline Source & Sequential p-value & Adjusted $\mathbf{R}^{\mathbf{2}}$ & Predicted R $^{\mathbf{2}}$ \\
\hline Linear & $<0.0001$ & 0.9007 & 0.8614 \\
2FI & 0.3999 & 0.9023 & 0.7999 \\
Quadratic & 0.3883 & 0.9032 & 0.7768 \\
\hline
\end{tabular}

Table 5: Sequential model sum of squares

\begin{tabular}{|c|c|c|c|c|c|c|}
\hline Source & Sum of squares & df & Mean square & F-value & p-value & \\
\hline Mean vs Total & 3.49 & 1 & 3.49 & & & \\
\hline Linear vs Mean & 0.0353 & 3 & 0.0118 & 52.41 & $<0.0001$ & Suggested \\
\hline 2FI vs Linear & 0.0007 & 3 & 0.0002 & 1.07 & 0.3999 & \\
\hline Quadratic vs 2FI & 0.0005 & 2 & 0.0002 & 1.05 & 0.3883 & Aliased \\
\hline Residual & 0.0020 & 9 & 0.0002 & & & \\
\hline Total & 3.53 & 18 & 0.1963 & & & \\
\hline
\end{tabular}

Table 6: Fit summary model for the measured responses R1 and R2 for the patch, response 2: \% drug release

\begin{tabular}{llll}
\hline Source & Sequential p-value & Adjusted $\mathbf{R}^{\mathbf{2}}$ & Predicted R $^{\mathbf{2}}$ \\
\hline Linear & $<0.0001$ & 0.7568 & 0.6455 \\
2FI & 0.0271 & 0.8611 & 0.7008 \\
Quadratic & 0.0279 & 0.9233 & 0.7644 \\
\hline
\end{tabular}

Table 7: Sequential model sum of squares

\begin{tabular}{|c|c|c|c|c|c|c|}
\hline Source & Sum of squares & df & Mean square & F-value & p-value & \\
\hline Mean vs Total & $1.004 \mathrm{E}+05$ & 1 & $1.004 \mathrm{E}+05$ & & & \\
\hline Linear vs Mean & 550.31 & 3 & 183.44 & 18.63 & $<0.0001$ & \\
\hline 2FI vs Linear & 75.96 & 3 & 25.32 & 4.50 & 0.0271 & Suggested \\
\hline Quadratic vs 2FI & 33.93 & 2 & 16.97 & 5.47 & 0.0279 & Aliased \\
\hline Residual & 27.93 & 9 & 3.10 & & & \\
\hline Total & $1.011 \mathrm{E}+05$ & 18 & 5614.83 & & & \\
\hline
\end{tabular}

Table 8: Analysis of variance table for measured responses for patch response 1: Tensile strength

\begin{tabular}{llllll}
\hline Source & Sum of squares & df & Mean square & F-value & p-value \\
\hline Model & 0.0353 & 3 & 0.0118 & 52.41 & 155.78 \\
A-HPMC 50 cps & 0.0350 & 1 & 0.0350 & 1.04 & $<0.0001$ \\
B-Ethyl cellulose & 0.0002 & 1 & 0.0002 & 0.4157 & 0.3247 \\
C-Almond oil & 0.0001 & 1 & 0.0001 & \\
Residual & 0.0031 & 14 & 0.0002 & \\
Cor Total & 0.0385 & 17 & & \\
\hline
\end{tabular}

The F-value of the model is 52.41 shows model is significant. P-values are less than 0.0500 indicate that the model is significant.

Table 9: Fit statistics (Tensile strength)

\begin{tabular}{llll}
\hline Std. Dev. & $\mathbf{0 . 0 1 5 0}$ & $\mathbf{R}^{2}$ & $\mathbf{0 . 9 1 8 2}$ \\
\hline Mean & 0.4406 & Adjusted R & 0.9007 \\
C. V. \% & 3.40 & Predicted R & 0.8614 \\
& & Adeq Precision & 17.1812 \\
\hline
\end{tabular}

The Predicted R2 of 0.8614 (table 4) is in reasonable agreement with the Adjusted R2 of 0.9007 ; i.e. the difference is less than 0.2 . A ratio greater than 4 is desirable. Here the ratio of 17.181 indicates an adequate signal (table 5). This model can be used to navigate the design space (fig. 1). 
Table 10: Analysis of variance table for measured responses for patch response 2: \% drug release

\begin{tabular}{llllll}
\hline Source & Sum of squares & df & Mean square & F-value & p-value \\
\hline Model & 626.26 & 6 & 104.38 & 18.56 & 83.31 \\
A-HPMC 50 cps & 468.50 & 1 & 468.50 & 3.59 & 0.0001 \\
B-Ethyl cellulose & 20.20 & 1 & 20.20 & 10.95 & 0.0846 \\
C-Almond oil & 61.61 & 1 & 61.61 & 0.0070 \\
AB & 59.24 & 1 & 59.24 & 0.9818 & 0.0078 \\
AC & 5.52 & 1 & 5.52 & 0.3430 \\
BC & 11.19 & 1 & 11.19 & 0.1859 \\
Residual & 61.86 & 11 & 5.62 & \\
Cor Total & 688.13 & 17 & & \\
\hline
\end{tabular}

The Model F-value of 18.56 (table 6) implies the model is significant and $0.01 \%$ chance that an F-value this large could occur due to noise. P-values less than 0.0500 indicate model terms are significant (table 7).

Table 11: Fit statistics (\% Drug release)

\begin{tabular}{llll}
\hline Std. Dev. & $\mathbf{2 . 3 7}$ & $\mathbf{R}^{2}$ & $\mathbf{0 . 9 1 0 1}$ \\
\hline Mean & 74.68 & Adjusted R $^{2}$ & 0.8611 \\
C. V. \% & 3.18 & Predicted R & 0.7008 \\
& & Adeq Precision & 15.9383 \\
\hline
\end{tabular}

The Predicted R2 of 0.7008 is an insensible agreement with the Adjusted R2 of 0.8611; for example, the thing that matters is under 0.2. A proportion more noteworthy than 4 is desirable. Here the proportion of 15.938 demonstrates a sufficient signal (table 8). This model can be utilized to explore the design space.

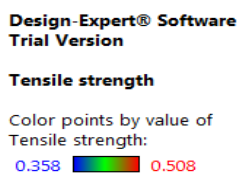

Tensile strength: 0.508

Design-Exper
Trial Version

\% Drug release

color points by value of

\% Drug release: 91.75

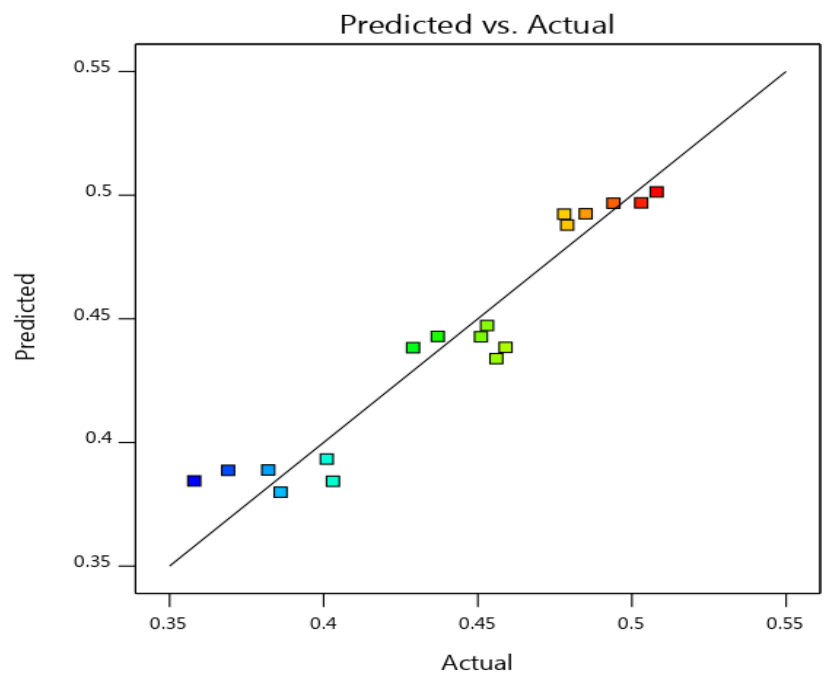

(a)

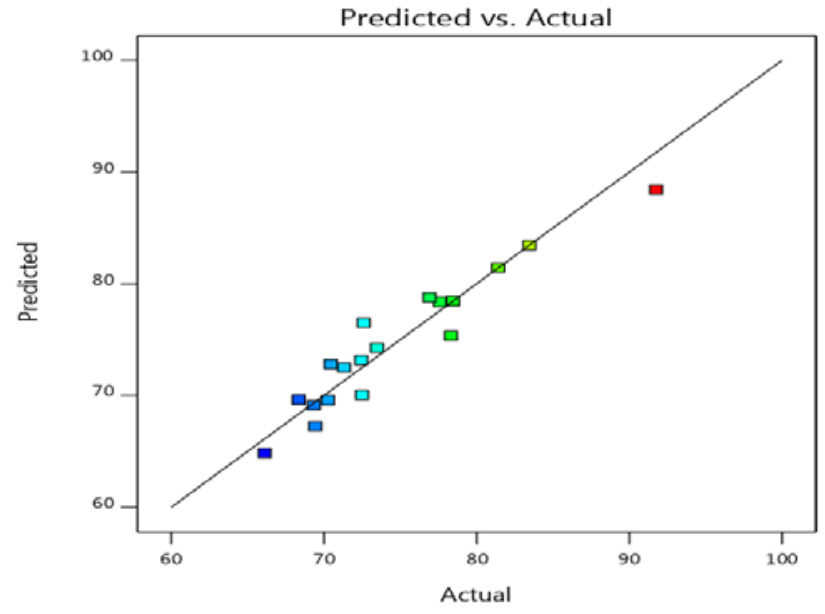

(b)

Fig. 1: Linear correlation plot (a) between actual and predicted values of the tensile strength (R1), (b) between actual and predicted values of \% drug release (R2) 
Design-Expert? Software

Factor Coding: Actual

Tensile strength $(\mathrm{Kg} / \mathrm{mm} 2)$ $0.358 \square 0.508$

$\mathrm{X}_{1}=\mathrm{A}: \mathrm{HPMC} 50 \mathrm{cps}$ $\mathrm{X} 2$ = B: Ethyl cellulose

Actual Factor
Design-Expert; Software

Tensile strength $(\mathrm{Kg} / \mathrm{mm} 2)$

$\mathrm{X} 1=\mathrm{A}: \mathrm{HPMC} 50 \mathrm{cps}$ $\mathrm{X} 2=\mathrm{B}$ : Ethyl cellulose $\mathrm{X} 3=\mathrm{C}$ : Almond oil

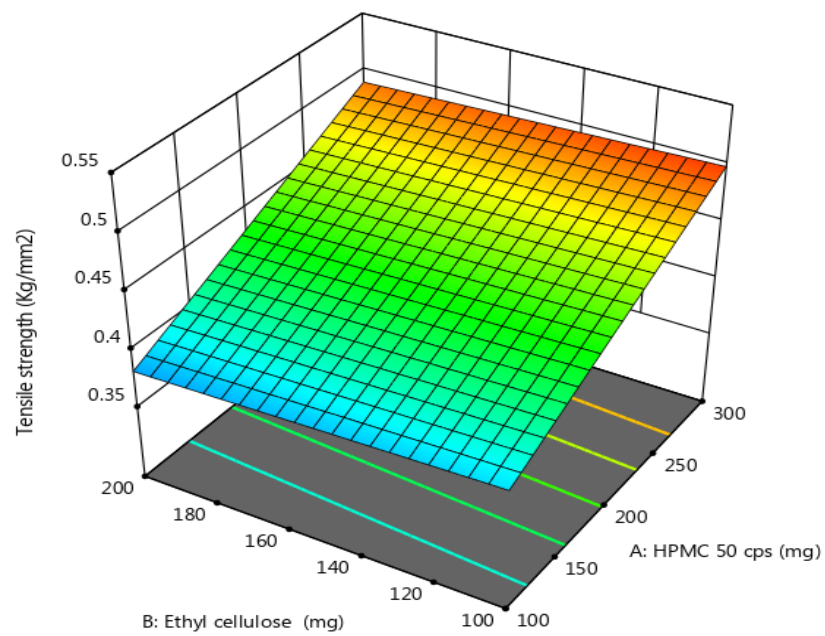

(a) Cube Tensile strength $(\mathrm{Kg} / \mathrm{mm} 2)$

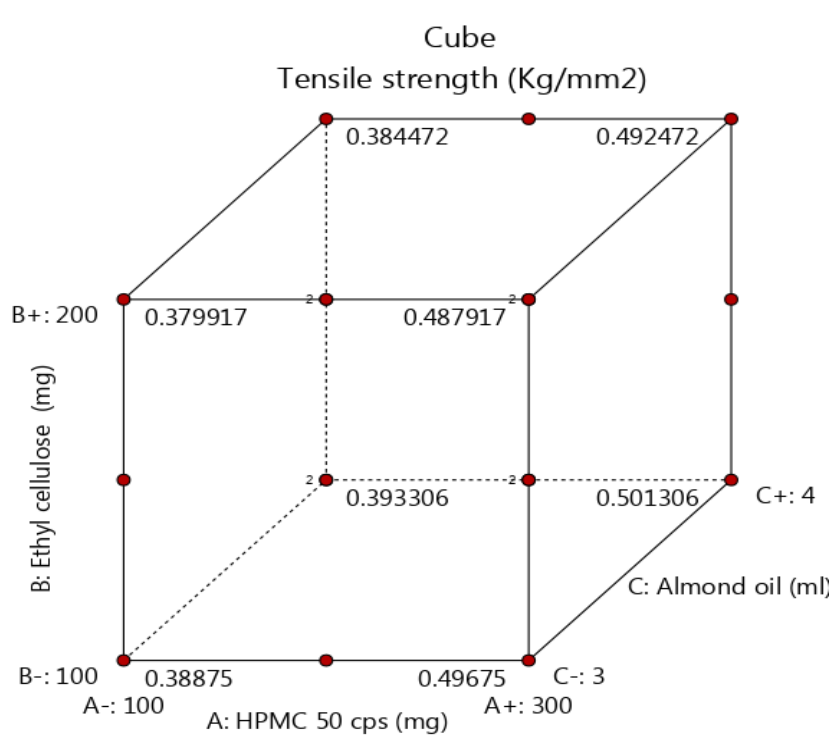

(b)

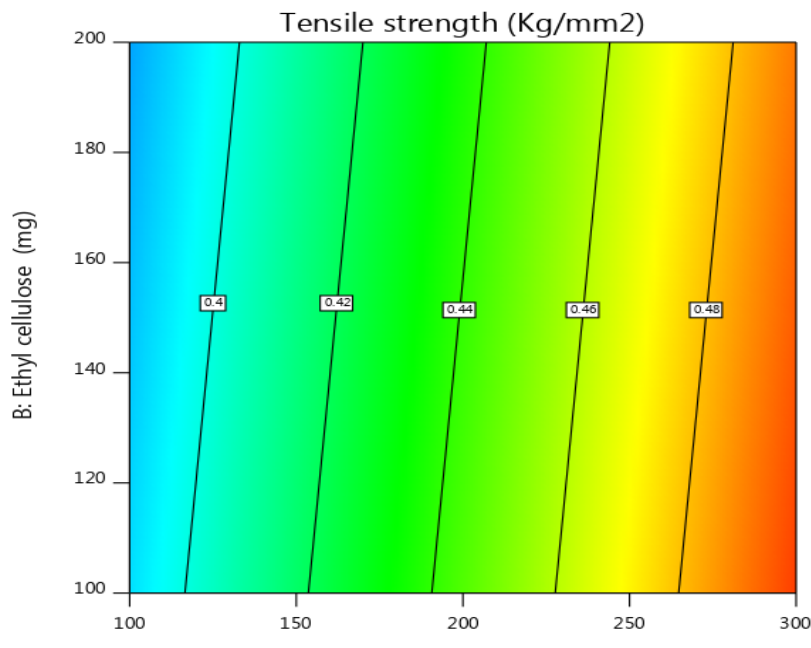

A: HPMC $50 \mathrm{cps}(\mathrm{mq})$

(c)
Design-Expert@ Software Trial Version

Tensile strength $(\mathrm{Kg} / \mathrm{mm} 2)$

$0.358 \square 0.50$

$\mathrm{X} 1=\mathrm{A}: \mathrm{HPMC} 50 \mathrm{cps}$
$\mathrm{X} 2=\mathrm{B}:$ Ethyl cellulos

Actual Factor
C: Almond oil $=3.5$

Fig. 2: Contour plot 3D response surface plot and a cubic plot showing the effect of HPMC and Ethylcellulose on response R1 (tensile strength) 
Design-Expert(8) Softwar Trial Version

Factor Coding: Actual

$\%$ Drug release (\%)

$66.12 \square 91.75$

$\mathrm{X} 1$ = A: HPMC $50 \mathrm{cps}$

cellulos

Actual Factor

Design-Expert (2) Software

Design-Expert
Trial Version

Factor Coding: Actual

$\%$ Drug release (\%)

$\mathrm{X} 1=\mathrm{A}: \mathrm{HPMC} 50 \mathrm{cPs}$

X2 = B: Ethyl cellulose

$\mathrm{X} 3=\mathrm{C}$ : Almond oil

Design-Expert (®8) Software

Trial Version

Factor Coding: Actual

$\%$ Drug release (\%)

$66.12 \square 91.75$

$\mathrm{X} 1=\mathrm{A}: \mathrm{HPMC} 50 \mathrm{cps}$

X2 = B: Ethyl cellulose

Actual Factor

C: Almond oil $=3.5$

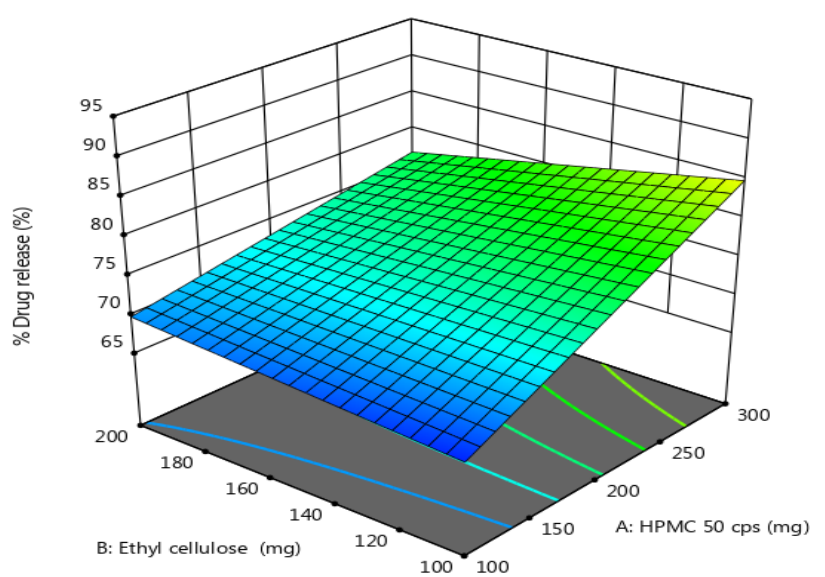

(a)

Cube

$\%$ Drug release (\%)

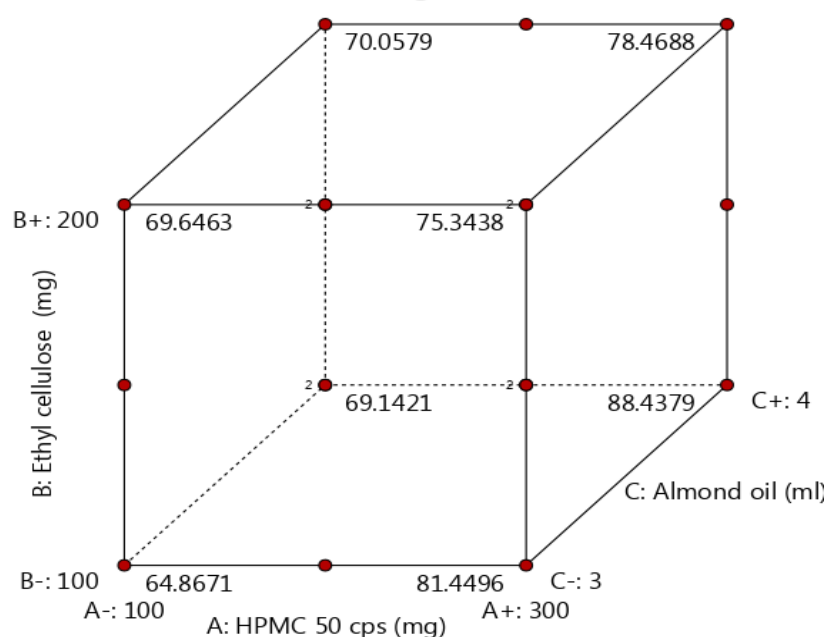

(b)

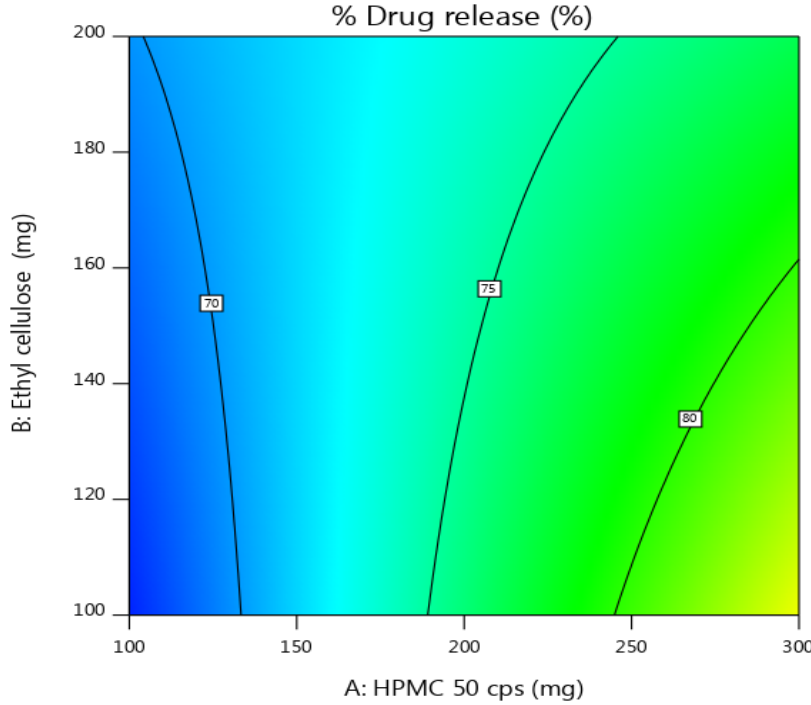

(c)

Fig. 3: Contour plot 3D response surface plot and a cubic plot showing the effect of HPMC and ethyl cellulose on response R2 (\% Drug release) 
Table 12: Optimized formulation factors

\begin{tabular}{llll}
\hline Factors & Optimum & & \\
\cline { 1 - 2 } HPMC & 200 & & \\
EC & 100 & & Prediction error (\%) \\
Almond oil & 3 & Observed Residual & 0.87 \\
Response & Predicted & $73.80 \pm 0.3$ & 3.97 \\
\%drug release & 73.16 & $0.4603 \pm 0.0176$ & \\
Tensile strength 0.4427 & & & \\
\hline
\end{tabular}

(Resudual $=$ predicted-observed value, Prediction error= Predicted value-Observed value/Predicted value*100)

\section{Effect of formulation variables on tensile strength of the film}

ANOVA used to assess experimental information and p-value estimation of regression coefficients utilized to measure significance, as shown in table 8. Tensile strength is a decent way to break down the mechanical properties of the film.

A delicate film has low percent lengthening and tensile strength while the hard and weak film is described by low stretching and moderate tensile strength. In this way, so to diminish the fragility of film and expand the flexibility of film required level of plasticizer is incorporated.

After adding plasticizer the tensile strength increases from 0.358 to 0.508. A linear model was seen to fit for the tensile strength response with a p-value and $F$ value of $<0.0001$ and 52.41. It was revealed that linear coefficients $(A, B, C)$ were noteworthy for the picked model. Pvalue was utilized to interaction strength quality among factors and centrality of individual coefficients (fig. 2). It is obvious from the response surface plot that the concentration of almond oil and HPMC 50 cps rate are the huge factors influencing the tensile strength in a positive way with a p-value of $<0.0001$. Permeation enhancers debilitate the attachment powers between polymer chains and hence improving the flexibility of polymer matrix $[13,14]$

The precision of the model to decide the tensile strength of the film was confirmed by the ANOVA of observed value, which yielded a linear relationship with $\mathrm{R}^{2}$ value of $0.8614 \mathrm{Kg} / \mathrm{mm}^{2}$ [15]. The linear equation generated by the software is given below:

Tensile strength $=0.329917+0.000540^{*}$ HPMC 50 cps $-0.000088^{*}$ Ethylcellulose $+0.004556^{*}$ Almond oil.
Effect of formulation variables on \% drug permeation of the film

ANOVA was utilized to assess experimental information and pestimation of regression coefficients were utilized to measure significance as appeared table. For the most part, the drug permeation is a decent tool to outline the dissolution attributes of the film [16, 17]. A film that has low drug permeation has poor disintegration properties (table 9). The utilization of the best possible level of permeation enhancer and the type and amount of hydrophilic/hydrophobic polymer improves (fig. 3) the medication release from the film [18].

The information exhibited that distinguished release percent ran from 66.12 to 91.75 . 2FI model was seen to fit for response \% drug release with a $\mathrm{p}$ and $\mathrm{F}$ value of 0.0271 and 4.50 . For this model linear coefficients, A and B were observed to be significant. P-value was utilized to decide the significance of individual coefficients and collaboration strength between factors. From response surface plot it is observed that the concentration of HPMC 50cps and oils are the major factors affecting the drug release percent in positive pattern with a p-value of 0.0271 . (table 10) The precision of the model was affirmed by the $\mathrm{R}^{2}$ value $(0.7008 \%)$ for patches as dictated by the ANOVA of the watched qualities, which yielded linear relationships (table 11). The linear equation generated by the software is given below:

\% Drug release $=+26.00917+0.096637 *$ HPMC 50 cps +0.218117 * Ethyl cellulose+6.78167* Almond oil-0.000544* HPMC $50 \mathrm{cps}$ * Ethyl cellulose+0.013567* HPMC $50 \mathrm{cps} *$ Almond oil-0.038633* Ethylcellulose* Almond oil.

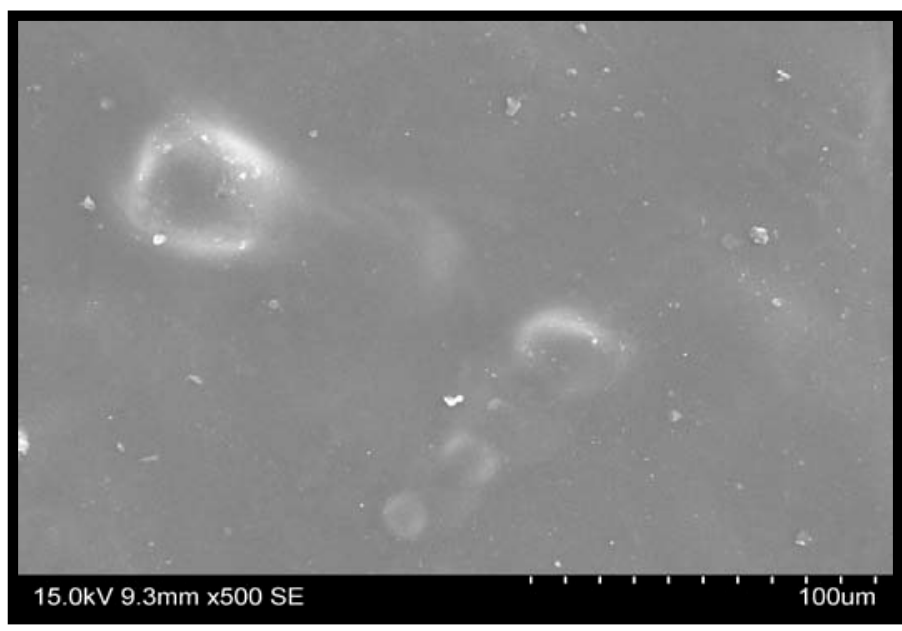

Fig. 4: SEM photograph of transdermal patch of HPMC 50 cps showing homogenous dispersion of drug in the patch

\section{DISCUSSION}

Transdermal patch prepared by the solvent casting technique was transparent, non-adhesive, homogeneous and smooth appearance. Phosphate buffer with tween 80 used for drug permeation study was optimal for drug release study. All the parameter like folding endurance, thickness, weight variation, Tensile strength, and \% drug release was also found near uniform and optimal.
Effect of formulation variables on the tensile strength of the film is a decent way to break down the mechanical properties of the film (fig. 4). A delicate film has low percent lengthening and tensile strength while the hard and weak film is described by low stretching and moderate tensile strength. It was observed in plotting another surface graph that, an increase in HPMC extent in the polymer blend gives higher tensile strength to the film. It revealed that with 
increment in the amount of EC (hydrophobic polymer), a decline in tensile strength was observed. It very well may be inferred that the preparation containing high convergence of HPMC $50 \mathrm{cps}$ and almond oils has higher tensile strength $[16,18]$

Effect of formulation variable on the percent drug release reveals that A film that has low drug permeation has poor disintegration properties. The utilization of the best possible level of permeation enhancer and the type and amount of hydrophilic/hydrophobic polymer improves the medication release from the film. From the equation, it is concluded that the two factors $\mathrm{A}$ and $\mathrm{C}$ have a positive effect on the \% drug permeation of the film. It was seen that the increase in HPMC $50 \mathrm{cps}$ and almond oils rate has a coordinate effect on the film's drug penetration. With the increase in oil amount (3-4 $\mathrm{ml}$ ) and HPMC 50 cps (300-100 mg) concentration, drug release was found to increment. linear correlation plots are shown among observed and anticipated values for the response. The predicted $\mathrm{R}^{2}$ value if there should be an occurrence of patches (0.7008) was in complete agreement with adjusted $R^{2}$ value $(0.8616)$ as the distinction between the two was observed to be under 0.2 . Permeation enhancers decline the lag time which happens because of a decline in diffusional path length of drug which is ascribed to changes in stratum corneum [19].

\section{CONCLUSION}

The transdermal patches of timolol maleate were prepared successfully. In the formulations increase in HPMC $50 \mathrm{cps}$ concentration results in the quicker dissolution of polymer matrix bringing about the development of channels for the dissemination of drugs from the film. Almond oils additionally add to great permeation of Timolol maleate. As a final point after investigation of experimental factors, an ideal formulation of Timolol maleate film containing almond oil with adequate medicament release and elongation was determined to contain $200 \mathrm{mg} \mathrm{HPMC} 50 \mathrm{cps}, 100 \mathrm{mg}$ Ethyl Cellulose and $3 \mathrm{ml}$ of almond oil. The anticipated values of responses for the optimized transdermal film were very close to the observed qualities with no extensive expectation error $\%$ and residuals. This result affirms that the optimization technique utilized is exceedingly solid and reproducible for the advancement of Timolol maleate patch with high-quality attributes.

\section{ACKNOWLEDGMENT}

I thank the School of Pharmaceutical Sciences, Jaipur National University Jaipur and Shri Ram College of Pharmacy, Karnal (Haryana) India for providing the necessary facilities for carrying out the work.

\section{AUTHORS CONTRIBUTIONS}

All the authors have contributed equally

\section{CONFLICT OF INTERESTS}

\section{Declared none}

\section{REFERENCES}

1. Strasser T. Addressing the entire risk profile. J Hum Hypertens 1990;4:51-3.
2. Kannel WB. Blood pressure as a cardiovascular risk factor: prevention and treatment. JAMA 1996;275:1571-6.

3. Lalji V, Gupta MM. Oral disintegrating tablet of antihypertensive drug. J Drug Delivery Ther 2013;3:85-92.

4. Peto R, Darby S, Deo SH, Silcocks P, Whitley E, Doll R. Smoking, smoking cessation, and lung cancer in the UK since 1950: combination of national statistics with two case-control studies. Br Med J 2000;321:323-9.

5. Kreatsoulas C, Anand SS. The impact of social determinants on cardiovascular disease. Can J Cardiol 2010;26:8C-13C.

6. Staessen JA, Fagard R, Thijs L, Celis H, Arabidze GG, Birkenhäger $\mathrm{WH}$, et al. Randomised double-blind comparison of placebo and active treatment for older patients with isolated systolic hypertension. Lancet 1997;350:757-64.

7. Gillman MW, Kannel WB, Belanger A, D'Agostino RB. Influence of heart rate on mortality among persons with hypertension: the framingham study. Am Heart J 1993;125:1148-54.

8. Jong WHD, Borm PAJ. Drug delivery and nanoparticles: applications and hazards. Int J Nanomed 2008;3:133-49.

9. Kumar P. Solid lipid nanoparticles incorporated cream of clobetasol-17-propionate: development and in vitro evaluation. Int J Pharm Sci Res 2018;9:5444-8.

10. Anitha P, Ramkanth S, Saleem MT, Umasankari K, Reddy BP, Chetty M. Preparation, in vitro and in vivo characterization of transdermal patch containing glibenclamide and atenolol: a combinational approach. Pak J Pharm Sci 2011;24:155-63.

11. Ren C, Fang L, Ling L, Wang Q, Liu S, Zhao L, et al. Design and in vivo evaluation of an indapamide transdermal patch. Int J Pharm 2009;370:129-35.

12. Nesseem DI, Eid SF, El-Houseny SS. Development of novel transdermal self-adhesive films for tenoxicam, an antiinflammatory drug. Life Sci 2011;89:430-8.

13. Saoji SD, Atram SC, Dhore PW, Deole PS, Raut NA, Dave VS. Influence of the component excipients on the quality and functionality of a transdermal film formulation. AAPS PharmSciTech 2015;16:1344-56.

14. Ahmed TA, Khalid M. Transdermal film-loaded finasteride microplates to enhance drug skin permeation: two-step optimization study. Eur J Pharm Sci 2016;88:246-56.

15. Kumar M, Trivedi V, Shukla AK, Dev SK. Effect of polymers on the physicochemical and drug release properties of transdermal patches of atenolol. Int J Appl Pharm 2018;10:683.

16. Fayez SM, Shadeed SG, Khafagy E-sayed A, Jaleel GAA, Ghorab MM, El-nahhas SA. Formulation and evaluation of etodolac lecithin organogel transdermal delivery systems. Int J Pharm Pharm Sci 2015;7:325-34.

17. Suksaeree J, Monton C, Charoonratana T. Morphology study of plai patch by the scanning electron microscope. Part I: chitosan and hydroxypropylmethylcellulose blends. Int J Pharm Pharm Sci 2014;6:576-7.

18. Jalhan S, Kaur K, Kaur P, K Jain U. Formulation and in vitro evaluation of transdermal matrix patches of doxophylline. Asian J Pharm Clin Res 2016;9:140-5.

19. Kibria G, Roni MA, Absar MS, Jalil RU. Effect of plasticizer on the release kinetics of diclofenac sodium pellets coated with Eudragit RS 30 D. AAPS PharmSciTech 2008;9:1240-6. 